\section{NINA CORCINSCHI}

Institutul de Filologie Română „Bogdan Petriceicu-Hasdeu” (Chişinău)

\section{EUGEN SIMION ȘI PROBA REVIZUIRILOR ESTETICE}

\title{
Eugen Simion And The test of Aesthetic Revisions
}

\begin{abstract}
In his volumes of Fragments, Eugen Simion resumes and blends his reflections on Romanian literature, culture and civilization. The Fragments VI tackles issues such as the aesthetics autonomy, the advantages and risks of revisions, the myths of the Romanian literature, the public and private morals of the writer, the limits of the compromise, the resistance through culture, etc. The plead for classics, the defense of great writers from the insults and the injustices of the day, the fight for the national values are part of a constant program of assuming everything that is essential and sustainable in the Romanian literature and culture. And it is a proof that the unwavering trust in the Romanian literature, doubled by the trust in the critic's vocation to work in the name of the aesthetic truth have remained intact over time in Eugen Simion's creation.
\end{abstract}

Keywords: revision, resistance, re-reading, aesthetic criterion, value redefinition.

Rezumat. În volumele sale de Fragmente, Eugen Simion reia și nuanțează reflecțiile sale asupra literaturii, culturii și civilizației românești. Fragmente VI dezbat probleme, precum autonomia esteticului, avantajele și pericolele revizuirilor, miturile literaturii române, morala publică și privată a scriitorului, limitele compromisului, rezistența prin cultură etc. Pledoaria pentru clasici, apărarea marilor scriitori de injurii şi nedreptăţile zilei, lupta pentru valorile naționale se înscriu într-un program constant de asumare a tot ce este esențial și durabil în literatura și cultura română. Aceste reflecţii şi pledoarii reprezintă dovada faptului că, în creația lui Eugen Simion, încrederea nestrămutată în literatura română, dublată de încrederea în vocația criticului de a lucra în numele adevărului estetic au rămas intacte de-a lungul timpului.

Cuvinte-cheie: revizuire, rezistență, recitire, criteriu estetic, redefinire valorică.

Spirit totalizator, înzestrat cu vocaţia marilor sinteze şi construcţii critice, Eugen Simion rămâne şi în seria Fragmentelor sale (8 la număr) un vizionar al întregului. Liniile de forţă ale sistemului său critic se regăsesc cu uşurinţă în aceste 
fragmente de reflecţii asupra literaturii şi culturii române, cu angrenajul lor de conexiuni sociale şi politice. Jurnalul public şi jurnalul liric depun mărturie despre profesiunea de credinţă a criticului, despre principiile sale etice şi estetice, despre o viaţă pusă în slujba literaturii.

Ideile şi credinţele criticului - recurente şi-n alte cărţi - sunt, în Fragmente VI (Simion, 2009), nuanţate şi repuse în discuţie. Pledoaria pentru clasici, apărarea marilor scriitori de injurii şi nedreptăţile zilei, lupta pentru valorile naţionale se înscriu într-un program constant de asumare a tot ce este esenţial şi durabil în literatura şi cultura română. Toate aceste reflecţii şi pledoarii reprezintă dovada faptului că, în creaţia lui Eugen Simion, încrederea nestrămutată în literatura română, dublată de încrederea în vocaţia criticului de a lucra în numele adevărului estetic au rămas intacte de-a lungul timpului. Viziunea unei critici estetice, pe linie maiorescian-lovinesciană, păstrarea şi promovarea marilor simboluri culturale şi arhetipuri literare ţin deopotrivă de o miză existenţială şi profesională. De dragostea pentru literatură. „Tot ceea ce am reuşit să fac, am făcut cu ajutorul literaturii şi tot ceea ce am devenit - am devenit prin şi cu ajutorul literaturii”, mărturisea Eugen Simion în cuvântarea din 2018 de la Academia Română. Literatura poate salva fiinţa umană, în particular şi societatea în general. Poate transforma viaţa unui om în destin. Poate salva societatea de impostură, de neantizare. O poate edifica naţional. Iată de ce criticul îşi asumă, în profesiunea sa, simbolul lui Mercuţiu, care semnifică dăruirea fără rest unei cauze nobile, devotamentul pentru cultură şi literatura de valoare. Iar locul său şi-1 găseşte în ariergarda avangardei, de unde „să-i aştepte cu răbdare şi cu spiritul deschis pe cei ce vin în literatură şi să-i recitească şi să-i redefinească estetic pe cei care sunt deja în literatură" (Simion, 2009, p. 479).

Recitirea (con)textului şi redefinirea estetică sunt jaloanele de bază care dau tonul şi ordonează dezbaterile din Fragmente VI despre autonomia esteticului, avantajele şi pericolele revizuirilor, miturile literaturii române, morala publică şi privată a scriitorului, limitele compromisului, rezistenţa prin cultură etc.

\section{Revizuirea estetică vs. revizuirea (u)morală}

Problema revizuirilor este una esenţială şi recurentă în reflecţiile lui Eugen Simion. Procesul literar este supus în mod firesc şi necesar reexaminărilor şi ajustărilor de nuanţă. Metodele de interpretare se modifică în timp, abordările capătă aspecte inedite, apar noi sensibilităţi critice şi noi „monştri sacri” ai literaturii, ierarhia valorilor e într-o perpetuă evoluţie. Până unde însă pot merge schimbările de optică, libertăţile de interpretare? Adept al lovinescianismului, Eugen Simion consideră inevitabilă în exerciţiul de revizuire a literaturii perspectiva estetică, care în sistemul axiologic - nu poate fi substituită de alte perspective: etice, politice 


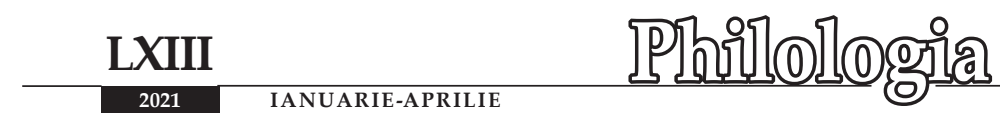

sau etnice.

Ofensiva revizuirilor postdecembriste n-a fost însă una bazată pe criterii estetice. Criticul constată cu amărăciune că, după totalitarismele sec. XX, energiile critice s-au dezlănţuit într-un mod anarhic, înlocuind de multe ori analiza echilibrată cu pamfletul zeflemitor, analiza atentă şi observaţia la rece cu revărsarea de umori. Clarificările contextuale n-au intrat în ecuaţia revizitării grăbite, furioase şi revanşarde a trecutului. Criteriul estetic a fost considerat reductiv şi chiar inoperant. Asistăm la o eroare de procedură, la o confuzie (voită?) de planuri, la intervertiri când elementele jenante, penibile din biografia unor mari scriitori iau în mod abuziv locul operei lor. Când cei care au pete accidentale în biografie (explicabile prin contextul social) sunt scoși la rampă, supuşi oprobriului public şi eliminați din literatură.

În această practică stradală, turbulenţele justiţiare exclud nuanţele. Nicolae Labiş şi Nichita Stănescu devin ,cobai ideologici”, Tudor Arghezi - specialist în ,,arta detractărilor şi a şantajului discret”, Mircea Eliade, Emil Cioran, Mihai Eminescu, Constantin Noica etc. sunt declaraţi ,,antisemiţi”, Marin Preda apare drept un oportunist lipsit de talent şi - culmea! - de nobleţe artistică, din cauza obârşiei sale ţărăneşti. La fel şi George Călinescu, care-l scandalizează pe Adrian Marino pentru că ar fi un fiu de servitoare. Mai mult, din perspectiva revizionismului tribal, unele texte de-ale lui Călinescu ar conţine ingrediente ale ideologiei ceauşiste şi ,teorii rasiste” şi ar da o conotaţie mistificatoare ideii de specific naţional, ridicând la puterea superlativelor o literatură mediocră. Şi mai gravă este culpa estetică care i se aduce marelui critic în legătură cu cedările din Scrinul negru. Dar putem judeca oare cu atâta uşurință, se întreabă Eugen Simion, un caz atât de special şi tragic, putem face oare abstracţie de faptul că a fost dat afară pentru totdeauna de la Universitate, că istoria a fost atât de potrivnică cu geniul său? Putem anula excepţionalitatea Istoriei literaturii române de la origini până în prezent pentru conformismele circumstanţiate istoric ale autorului? E de ordinul evidenţei că nu! La fel, a vorbi deschis despre Mitrea Cocor, a lui Mihail Sadoveanu, nu e totuna cu a anula întreaga operă a scriitorului. Sau poemele de compromis ale lui Stănescu nu-l descalifică drept poet autentic, nu-i maculează opera în ansamblu. Una-i una, și alta-i alta. Criteriul moral nu poate fi un argument solid în situarea axiologică a unei opere. Reţin aici observaţia lui Marin Mincu de a ţine cont de o cerinţă „metodologică” de disociere între ,,ipostaza «istorică» a individului anagrafic şi aceea «metafizică» a creatorului de valori'. Astfel, ,,aplicând pedestru o metodă anecdotică, putem descoperi oricând nenumărate defecte, ascunse laşităţi şi fireşti meschinării umane ce aparţin, documentat sau nu, chiar biografiei unora dintre scriitorii cei mai importanţi!" (Mincu, 2009, p. 501).

În ceea ce priveşte perioada postcomunistă, e clar că detabuizările literare, denunţul canonizărilor politice etc. au fost necesare şi utile. După decenii 
proletcultiste de mistificare a literaturii, revizuirile sunt inevitabile pentru restabiliri de ierarhii şi redefiniri axiologice. Istoria literară trebuie să ofere tabloul întreg, cu toate luminile şi penumbrele sale. Dar acest proces de regândire atentă şi judicioasă a trecutului e cazul să-1 facă specialiştii, criticii şi istoricii literari - consideră Eugen Simion -, nu jurnaliştii improvizaţi. Se cunosc bine efectele revizuirilor politice ale literaturii naţionale de după 1944, declanşate de către ideologii luptei de clasă marxist-leniniste, care au falsificat într-un mod extrem de toxic cultura românească. Problemele de axiologie literară nu pot fi lăsate pe seama detractorilor deghizați în spirite justiţiare, care încearcă să răstoarne în mod tendenţios sistemul de valori.

Eugen Simion rămâne pe poziţiile sale axiologice ferme în ceea ce privește autonomia esteticului. Valoarea operei, crede istoricul literar, nu trebuie confundată cu valoarea morală a omului ce o scrie. Revizuirea morală, când a funcţionat în afara unui criteriu estetic, a sucombat în idiosincrazie şi delaţiune agresivă. În răfuială, crede Eugen Simion. „Cine a avut de plătit o poliţă, o plăteşte pe această cale. O răfuială, o hărmălaie, o hărţuire stupidă şi, în cele din urmă, inutilă pentru că, am spus de atâtea ori, pamfletul nu lămureşte nimic când e vorba de un fenomen tragic în istorie" (Simion, 2009, p. 302).

De aceea, recursul la metoda Lovinescu, de a nu confunda eticul cu esteticul şi etnicul, este esenţial în discursul critic al lui Eugen Simion. Cumpănitor şi prudent, criticul propune un reglaj de nuanță în ecuaţia autor - operă literară - context. Programul de revizuiri trebuie să dispună de instrumente diferite în evaluarea biografiei autorului şi a operei sale. În cazul culpei estetice, criticul trebuie să depisteze cum alterează aceasta substanța întregului, iar în cazul culpei morale cât de mare e compromisul cu ideile, cât de grav a fost răul provocat. Trebuie să cunoaştem biografia politică a marilor scriitori, în numele restabilirii adevărului în istoria literară. În aceste condiţii, criticul e obligat să fie ,atent la circumstanţe, încercând să înţeleagă tragedia din interiorul unei istorii urâte, neignorând, mai ales, faptul esenţial că acela care a acceptat un compromis regretabil este un poet important, poate un mare poet” (ibidem, p. 301). Opera literară însă se evaluează cu altă unitate de măsură - cu cea estetică. Doar aceasta poate depune mărturie despre valoarea operei. Aşa cum un mare scriitor care a trădat politic nu poate fi disculpat prin importanţa operei sale, nici opera, la rândul ei, n-ar trebui să poarte stigmatul biografiei autorului.

O altă confuzie ţine de biografia publică şi de biografia intimă a scriitorului. Căutarea prin viaţa intimă a scriitorului este o insanitate. „Una este culpa politică sau culpa morală (acestea pot interesa opinia publică) pentru că vin în atingere cu biografia publică a autorului şi alta este biografia intimă a autorului. Pe aceasta din urmă nimeni nu este îndreptăţit s-o cerceteze" (ibidem, p. 184).

Şi nu ultima confuzie în interpretările de după ' 90 e între ideologia autorului și creaţia lui. Eugen Simion dă cel mai la îndemână exemplu - pe Mihai Eminescu, atacat la nesfârșit de contemporani pentru ideile sale politice. Precizarea criticului 


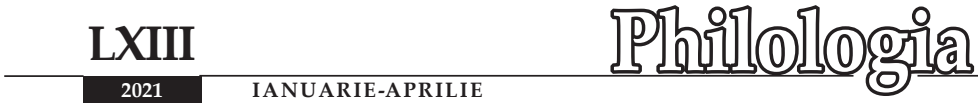

e de nuanţă, de receptare diferenţiată a poetului şi a publicistului. Din punct de vedere politic, Eminescu este un conservator, un antiliberal. Poezia acestui conservator însă a modernizat întreaga lirică a secolului.

Încercările de demolare a valorilor fundamentale sunt mereu sortite eşecului prin rezistenţa intrinsecă a acestora. Canonul se apără singur, remarca Ion Simuț în cartea sa Literaturile române postbelice: ,nu sunt eu conservator, ci acest canon are inerţia de a rezista, indestructibil. Eu nu am făcut decât să constat acest fenomen, care scapă celor cu o cultură literară precară” (Simuţ, 2017, p. 466). Modificarea orizontului de aşteptare al cititorului, mai cu seamă în contextul metamorfozelor psiho-culturale care se întâmplă după mari zguduiri istorice, încurajează ,,ambiţiile generaţioniste” (Paul Cernat) sau chiar ,infatuările generaţioniste” (Ion Simuţ) de a opera mutaţii în sistemul de valori. E un proces cât se poate de firesc de reglaj axiologic, de afirmare a noilor pretendenţi la gloria literară prin exerciţii de negare a predecesorilor. Efectul însă trebuie să fie constructiv, cu discernământ, nu distructiv, demolator, revanşard. În toate cazurile dificile, complexe, de ajustare corectă a raportului autorului cu opera şi contextul, Eugen Simion propune autoritatea judecăţii critice şi soluţia metodologică: ,a spune adevărul despre operă este mai important decât a interzice pe omul care a scris-o" (ibidem, p. 307).

\section{Vânătoarea de mituri}

Victimă a revizionismului tendenţios de după anii '90 este şi mitologia naţională, adică valorile fixate în conştiinţa publică. Revenirea obligatorie (prin autorităţi instituţionale) la clasici e percepută de unii critici ca „efervescenţă mitogenetică” (E. Negrici) cu grave consecinţe de „viol estetic”, de cultivare a ,instinctului mimetic”, de manipulare a gustului estetic al cititorului şi fundătură a conformismului etc. Au de pătimit şi ,,avocaţii” modelelor clasicităţii. George Călinescu (ca şi Tudor Vianu sau Vladimir Streinu) este repudiat pentru pledoariile lui în favoarea clasicismului, a „ceea ce este esențial, durabil, repetitiv în literatură”. Adică a ceea ce înţeleg cârtitorii prin „defazat” şi „,expirat”. În pusee pamfletare demagogice sunt înfierate miturile fondatoare ale literaturii române şi se neagă cu o uşurinţă sfidătoare originalitatea şi organicitatea literaturii române. Argumentul lui Eugen Simion este de bun-simt,, imbatabil. Modelele nu sunt strivitoare decât pentru creatorii mediocri. Pentru scriitorii buni - sunt stimulative. Iar valoarea unei literaturi n-o decid epigonii penibili, scriitorii de duzină. A argumenta „toxicitatea modelelor" prin grafomanii imitatori este o eroare de metodă.

De fiecare dată, în astfel de exagerări şi derapaje de interpretare, criticul avertizează despre confuzia planurilor. Autorul este substituit cu interpretul operei. Textul - cu seria de determinări şi contexte extraestetice. Ce vină au autorii că sunt interpretaţi într-un fel sau altul? Ce vină o fi având aceste modele, repere înalte ale culturii naţionale că devin victime ale unei retorici inflamate a epocii? Că inspiră spiritele clamoroase, demagogii, conjuncturiștii de toată mâna să fabrice slogane, 
să producă maculatură? E acesta un motiv să ne dezicem de clasici? E ca şi cum ai amenda un medicament nu pentru ceea ce tratează, ci pentru efectele secundare neînsemnate pe care le provoacă. Degringolada este inevitabilă, bâlciul este asigurat într-o cultură prin însăşi dinamica crizei care bântuie orice epocă. Atitudinea festivistă, encomiastic-delirantă există, aşa cum există şi cea denigratoare, nihilistă. Acestea vor însoţi în mod inevitabil procesul literar, ca un zgomot de fond şi ca o consecinţă a imposturii, care este a istoriei (evacuarea ideologică a modelelor din cultură, totalitarismele de tot felul etc., care au impulsionat defulările zgomotoase), şi nu a marilor scriitori. Ierarhia valorilor o asigură însă spiritele lucide, criticii şi istoricii literari care impun simţul măsurii, rigoarea estetică, judecata de valoare. Criticul autentic ,remarcând cearta dintre zelatorii şi delatorii unei opere literare, nu dinamitează opera, ci face ceea ce trebuie: restabileşte traiectoriile reale ale operei. Oricum, el nu trebuie să intre în panică din cauza miturilor (false) şi complexelor de orice fel care, inevitabil, proliferează nu atât în literatură, cât în preajma ei” (ibidem, p. 154).

Cel mai expus demitizării furioase este, din punctul de vedere al lui Eugen Simion, mitul eminescian. Cu referire la Eminescu, criticul identifică câteva feluri de abuzuri în publicistica românească. Mai întâi, poetul serveşte drept pretext de pamflete pentru zeflemitorii de serviciu, care se declară sastisiţi de ,atâta Eminescu”. Mai apoi, devine victima adulatorilor necritici, a „localiştilor fanatizaţi”" care nu mai contenesc cu clişeele encomiastice, dar şi victima scepticilor internaţionalişti, care se însoţesc cu argumente ideologice, numindu-1 „xenofob” şi „,rasist”, într-o nedreaptă ignorare a circumstanţelor epocii în care a trăit. Astfel, pamfletul a înlocuit analiza, umorile au luat locul detaşărilor obiective, revizuirea necesară pentru ajustările fenomenului literar la noi optici critice a devenit execuţie publică. Adus la banca acuzaţiilor şi făcut responsabil de toată mitologia care-i poartă numele, Eminescu e înfierat că ar avea un rol distructiv asupra culturii noastre. Confuzia este de ordinul evidenţei. Ce vină are poetul pentru existenţa acestor „scrântiţi întru Eminescu”? cum îi numeşte Eugen Negrici. Sau ce vină are Călinescu că i-au fost preluate şi transformate în clișee cuvintele adevărate pe care le-a spus despre Eminescu?

Astfel de interpretări denotă o poziţionare ,pe lângă” subiect, semnalează actul de a ,pune strâmb chestiunea”. Ideea că miturile ne-ar ţine într-o condiţie de primitivism cultural şi că trebuie să ne dezicem de ele, lui Eugen Simion i se pare complet aberantă. Şi pe bună dreptate. Demolarea miturilor trebuie înlocuită cu revizuirea - adică interpretarea acestora din perspective hermeneutice noi, cu identificarea modului în care miturile reverberează estetic în literatura noastră de azi.

Toate aceste bătălii de idei pe care Eugen Simion le-a purtat de-a lungul timpului cu adversarii săi demonstrează faptul că criticul nu este nicidecum un spirit apolitic, neangajat în treburile cetății, aşa cum i s-a imputat adesea. Apărând valorile naţionale, exegetul desfăşoară o acţiune cât se poate de 


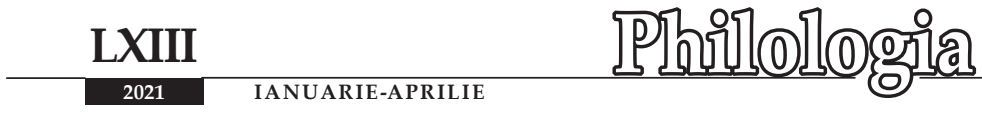

patriotică. Opera lui Eugen Simion îşi conţine propria disidenţă. Recuperarea lui Eugen Lovinescu, în 1971, când criticul interbelic era încă izgonit din istoria literaturii de ideologia proletcultistă, este un act de curaj şi demnitate critică. Studiul Eugen Lovinescu, scepticul mântuit pune problema rolului major pe care 1-a avut Lovinescu în mutaţiile de percepţie estetică de după 1919 şi îi restabileşte locul binemeritat în ierarhia valorilor literare. Un act similar de disidenţă artistică se conţine în studiile despre scriitorii din exil - întreprindere temerară pentru perioada de până la 1989. Apoi, promovând aceleaşi valori, vin cercetările academice de mare amploare coordonate şi studiile de autor: Dicţionarul General al Literaturii Române, colecţia Opere fundamentale, de tip Pleiade, facsimilarea Caietelor lui Eminescu (visul lui Constantin Noica), Enciclopedia literaturii române vechi, trilogia despre Ficţiunea jurnalului intim, dipticul Genurile biograficului, seria Scriitori români de azi (o adevărată mană cerească pentru studenţii filologi), studiile fundamentale despre marii scriitori Mihai Eminescu, Ion Creangă, Eugen Lovinescu, Eugen Ionescu, Mircea Eliade, Emil Cioran etc. - toate proiecte naţionale de anvergură europeană.

Polemicile cu revizioniştii politizaţi pentru apărarea valorilor umaniste, a clasicilor, a scriitorilor de referinţă ai literaturii - sunt, în temei, proiecte edificatoare de cultură. Ce altceva sunt dacă nu construcţii de interes naţional?

\section{Sansele literaturii, rațiunile criticii}

În viziunea lui Eugen Simion, literatura şi critica se intercondiţionează într-un mod organic. Critica, crede exegetul, va avea viitorul pe care îl va avea literatura română. E bine ştiut că o literatură bună va „creşte”, negreşit, şi interpreţi pe potrivă. Raţionamentele acestei meserii se sprijină, aşadar, pe scriitorii mari şi pe necesitatea de a-i aduce în conştiința publicului. De aceea, de „răul de literatură”, criticul se salvează prin scriitorii autentici. Încrederea în rostul criticului o alimentează literatura de calitate, modelele scriitoriceşti. „Aşa se întâmplă ori de câte ori simt că existenţa devine insuportabilă şi critica literară îmi pare o deşertăciune... Deschid opera unui clasic şi spiritul meu, bolnav, copleşit de scepticism, îşi recapătă forţele, iar dorinţa de-a merge mai departe reînvie în mod spectaculos" (ibidem, p. 467). Criticul Andrei Țurcanu făcea o mărturisire similară despre faptul că n-a renunţat la scris în vreme de restrişte, datorită literaturii de calitate: ,întâlnirea cu o carte bună a însemnat pentru mine în continuare, ca întotdeauna, o revărsare a simţurilor, a emoţiilor şi a gândului într-o jubilaţie unică, pură, inconfundabilă" (Țurcanu, 2020, p. 6). Încrederea în scriitură, învingerea ,răului de literatură" (pe care o resimt mai cu seamă cei împătimiți de ea) nu pot fi întreţinute decât prin modele, prin reprezentanţii de vârf ai unei culturi, care inspiră spiritul şi stimulează tensiunea creaţiei. Reperele intelectuale şi morale ale criticului au fost George Călinescu, Tudor Vianu, dar mai cu seamă Eugen Lovinescu. „Dacă este vorba de sacrificiu, demnitate, sensibilitate, iubire spirituală, deschidere spre cei ce vin în literatură, 
receptivitate critică şi un puternic, irepresibil sentiment de justiţie în literatură, atunci este vorba de E. Lovinescu. De numele său se leagă toate aceste calităţi care asigură onoarea şi forţa disciplinei noastre: critica literară" (ibidem, p. 469). Din perspectiva acestei opţiuni critice, simbolul asumat de Eugen Simion - al lui Mercuţiu - se însoţeşte cu cel al lui Toma Necredinciosul. Credinţa nestrămutată în rostul literaturii se sprijină pe scepticismul inerent al criticului, care are mereu nevoie să verifice, să recitească, să revizuiască şi să se convingă cu proprii ochi cum stau lucrurile.

Judecata bine cumpănită şi echilibrul spiritului - calităţi ale lui Eugen Simion, remarcate de mai mulţi critici,-- sunt, dacă ne luăm după dezvăluirile criticului, nu neapărat un dat temperamental, ci ţin mai curând de o disciplină a muncii, de principii deontologice ale scrisului. Astfel, criticul nu ascunde faptul că este un spirit neliniştit, o fire zbuciumată, un „,anxios solar”. „Sunt un sentimental care-şi stăpâneşte cât de cât bine anxietăţile" (ibidem, p. 438). Literatura îi provoacă smerenia estetică, în definire proprie - resemnarea estetică. Criticul nu are rost să-şi piardă vremea cu scrisul, dacă nu ştie să se detaşeze de raportul său cu autorul şi să privească în text cu obiectivitate şi simţ al dreptăţii. E axiomatică afirmaţ̧ia sa: „,criticului literar îi trebuie puţină umilinţă faţă de operă. Îi stă bine modestia, chiar dacă, în fiinţa noastră, orgoliul este gata să plesnească... Opera este prioritară şi critica să facă bine să accepte, strategic, această prioritate. Chiar dacă, în secret, gândeşte că, fără el, opera rămâne un maldăr de foi mâzgălite..." (ibidem, p. 451).

În logica acestui program critic, textele lui Eugen Simion sunt probe de judecată atentă şi chibzuită. Sfatul criticului către tineri este să nu lase idiosincraziile personale să le tulbure perspectiva dreaptă asupra operei - sfat legitimat prin propriul exemplu. Polemica echilibrată cu adversarii de idei, observaţiile judicioase şi afirmaţiile de bun-simț ale preopinentului sunt remarcate şi în cele mai aprige dispute. Eugen Simion nu se fereşte să le aprecieze, aşa cum nu ezită să demaşte, cu o nedisimulată revoltă uneori, falsurile şi manipulările din textele adversarilor. Pentru a apăra marii scriitori de atacurile nedrepte ale ideologilor cârtitori, criticul îşi pune la bătaie toată recuzita de argumente critice şi de fiecare dată aduce lucrurile pe făgaşul lor normal. Exegetul îşi păstrează şi în cele mai aprinse discuţii distincţia gestului şi eleganţa exprimării, atenţia maximă la detalii, luciditatea nealterată de nicio înfiorare emoţională.

Lectura lentă, „lectura gânditoare”, popasul în text, reflecţia negrăbită în marginile semnificaţiilor textului sunt jaloanele esenţiale ale programului său critic. Scriind despre autorii din comunism, Eugen Simion şi-a cultivat răbdarea de-a înţelege circumstanţele în care s-a manifestat un creator, de a surprinde cu fineţe mişcările sinusoidale ale talentului într-o epocă ostilă spiritului liber. Doar printr-o abilă coordonare a criteriului estetic cu mişcările tectonice ale istoriei, operele comentate de critic s-au putut poziţiona corect pe harta literaturii. 


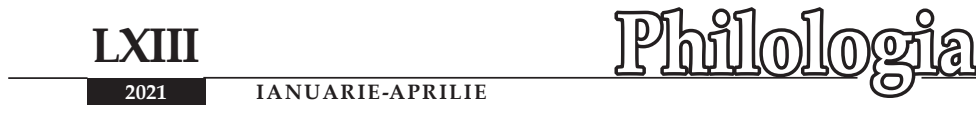

\section{Reinventări necesare}

În civilizaţia capricioasă a spectacolului, şansa unui critic de a-şi păstra ceva din prestigiul de altă dată este, pe lângă rigoarea critică, originalitatea creativă. În fapt, visul unui critic e să devină un eminent „,prozator de idei”, scrie Eugen Simion. Să fie citit pentru el însuşi. Adică să aducă discursul critic la demnitatea literaturii: „uneori limbajul criticului are nevoie nu de panglici şi ciucuraşi, nici de o bâtă noduroasă, ci de un şal de mătase care să îmblânzească privirea cititorului" (ibidem, p. 451).

La marii creatori, imaginaţia ideilor se articulează (aşa cum admiră criticul la Constantin Noica sau la Albert Thibaudet, Roland Barthes etc.) într-o naraţiune care se ridică la rang de artă. În acest sens, pentru Eugen Simion, lecţia George Călinescu asta a fost - timbrul personal al discursului, spectacolul ideilor. Sau lecţia Eugen Lovinescu, judecat iniţial printr-o optică împrumutată de la Ibrăileanu şi admirat mai apoi pentru noutatea observaţiilor critice şi ,calităţile stilului său percutant şi artistic". Iar lecţia lui Jean-Pierre Richard (probată cu succes în Dimineaţa poeţilor) face să palpite în subteranele textului senzorium-ul fiinţei, imaginarul simţurilor.

Lecţia Eugen Simion - putem spune - continuă în mod creator spectacolul hermeneutic al înaintaşilor prin subtilitatea analizei, percutanţa ideii și rafinamentul expresiei. În cărţile sale, simţul critic al disocierilor fine şi al judecăţilor de valoare ferme şi probante se conjugă cu un admirabil simţ epic care dezvoltă observația critică într-o demonstraţie narativă originală. Volumele Scriitori români de azi se citesc ca naraţiuni cu portretizări formidabile, cu impresionante volute interpretative şi care, în timp, şi-au păstrat intacte esenţele critice prin surprinderea exactă a timbrului autentic al vocii autorului analizat şi prin contextualizările fine, fără de care un scriitor din acea vreme nu poate fi receptat cu deplină înţelegere.

La fel studiul Dimineața poeților, cu un discurs seducător, favorizat şi de voluptăţile temei, este o veritabilă proză de idei. Subtilitatea formulărilor, acuitatea observaţiilor se articulează într-un neaşteptat de savuros discurs despre poezia vechilor înaintaşi. Erudiţia criticului se însoţeşte de simţire, empatia nu părăseşte judecăţile de valoare, textul este un discurs personalizat, am putea spune un poem critic. Criticul adaptează o poetică demult apusă la sensibilitatea artistică a contemporanilor, împrospătează vocile poeţilor cu inflexiuni moderne, îi aduce în orbita estetică a prezentului printr-un subtil act creator. Mai pot fi citiţi la fel plictisitorii, la prima vedere, Anton Pann, poeţii Văcăreşti, Grigore Alexandrescu, Vasile Cârlova, Dimitrie Bolintineanu etc. după studiul lui Eugen Simion? $\mathrm{Nu}$, cu siguranţă! Trecuţi prin laboratorul de creaţie al criticului, aceştia au devenit personaje moderne, de o sclipitoare vitalitate şi de un subtil simţ artistic.

Noile grile de lectură, provocările teoriilor moderne de interpretare reprezintă proba de erudiţie şi de creativitate pentru orice critic. Pentru Eugen Simion, literatura nu este (doar) o sumă de convenţii şi strategii teoretice. Intoarcerea autorului pune apăsat problema eliberării autorului din captivităţile teoretice. După experimentele structuraliste şi poststructuraliste, după îndrăzneţe aventuri ale 
scriiturii, literatura ar trebui să redevină umanizatoare. Să iasă din discursul despre sine şi să pună accentul pe om, pe dramele vieţii, pe condiţia umanului într-un timp al post-umanului, aşa cum critica ar trebui să descopere „,nu numai semnele, dar şi sensurile textului..." (ibidem, p. 293). Se pare, astăzi cititorul nu mai poate fi întors la literatură prin experimente elitiste, prin metaroman, roman autoreferenţial, ci prin substanţa epicului. „Romanul, indiferent pentru ce formulă optează, trebuie să spună ceva despre condiţia existenţială a omului de azi şi de ieri..." (ibidem, p. 293). Acestea sunt sfaturile pe care le dă criticul tinerilor scriitori: să se reinventeze. Să reinventeze critica literară ca instituţie, să-i recâştige prestigiul şi eficienţa. Să reinventeze poezia şi să-şi formeze cititorii, dacă aceştia lipsesc. Prozatorii să folosească cuceririle noilor poetici şi să treacă la formule noi de roman. Să-şi reinventeze epica şi să rescrie „povestea Marchizei care, la ora cinci, coboară din blocul ei de pe strada Sapientei şi se îndreaptă, pentru a se întâlni cu cineva, spre Sfinţii Voievozi..." (ibidem, p. 293). Miza e să nu se piardă literatura română.

Eugen Simion a creat cât o instituţie de cultură. Proiectele-i sunt monumentale, opera e de o anvergură impresionantă, iar cultura umanistă la care a trudit o viaţă "«ţine» intregul împreună" (Paul Cernat). Situat intim şi organic în literatura română, Eugen Simion este pilonul de forţă al unui sistem axiologic pus mereu la încercare de istorie. Spiritul lui drept, competenţa şi autoritatea judecăţilor sale critice păstrează în echilibru dreapta cumpănă a valorilor. Dacă critica va avea viitor doar prin rezistenţa literaturii în timp, axioma e valabilă şi în sens invers: literatura de calitate se salvează prin critică. Prin critici care reprezintă împlinirile de graţie ale unei culturi, etalonul de forţă al literaturii. Prin tot ce a realizat, Eugen Simion este, neîndoios, un etalon. Literatura postbelică îi datorează enorm.

\section{Referinţe bibliografice:}

MINCU, Eugen. Gălăgia demolatoare. În: Luceafărul, nr. 22, 10 iunie, 1998. Reluat în: MINCU, Marin. Cvasitratat de/spre literatură ( $A$ fi mereu în miezul realului). Piteşti: Paralela 45, 2009.

SIMION, Eugen. Fragmente VI. Bucureşti: Fundaţia Naţională pentru Ştiinţă şi Artă, 2010.

SIMUȚ, Ion. Literaturile române postbelice. Cluj-Napoca: Editura Şcoala Ardeleană, 2017.

ȚURCANU, Andrei. Critice. Arheul marginii şi alte naraţiuni. Chişinău: Cartier, 2020.

Notă: Articolul a fost realizat în cadrul proiectului de cercetare 20.80009.1606.03 Contexte socioculturale autohtone şi interconexiuni europene în creaţia populară şi literatura cultă din Basarabia (sec. XIX până în prezent), Institutul de Filologie Română „B. P.- Hasdeu” al MECC. 